\title{
Sharing the burden of climate change stabilization: An energy sector perspective
}

\author{
Fabian Wagner \\ International Institute for Applied Systems Analysis \\ (IIASA), Schlossplatz 1, 2361 Laxenburg, Austria \\ Jayant A. Sathaye \\ International Energy Studies Group, \\ Lawrence Berkeley National Laboratory, \\ 1 Cyclotron Road, Berkeley CA 94720-8136, USA
}




\begin{abstract}
In this paper we discuss long-term least cost $\mathrm{CO}_{2}$ stabilization scenarios based on the SRES AIM A1B scenario in the context of an international burden-sharing regime. Starting from a stabilization target, regional emission caps are formulated dynamically on the basis of past emissions. With these regional caps, the cost-optimal supply fuel mix in the energy sector in the four SRES world regions is calculated, and lower bounds on the volume of traded carbon are estimated. The allocation scheme provides incentives for early mitigation action. We estimate additional regional costs incurred by the allocation scheme, and assess the sensitivity of results to changes in the concentration ceiling, discount rates, and start date for burden sharing.
\end{abstract}

Keywords: Climate mitigation; Burden sharing; Stabilization 


\section{Table of Contents}

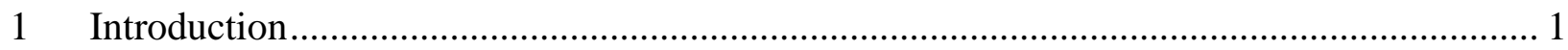

2 Methodology and model approach........................................................................ 2

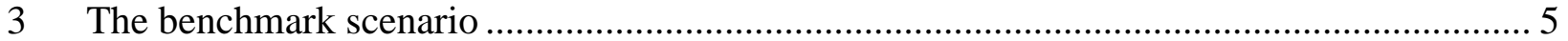

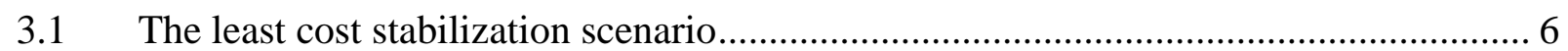

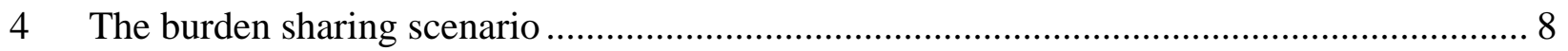

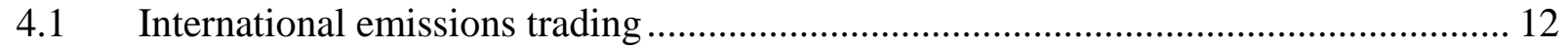

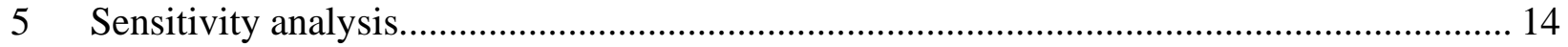

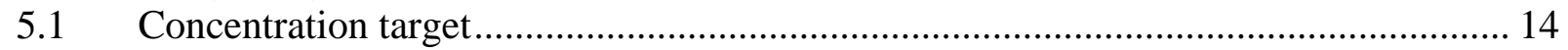

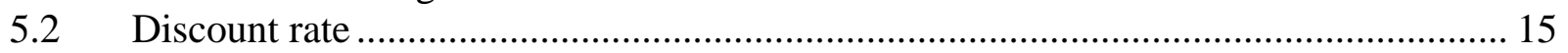

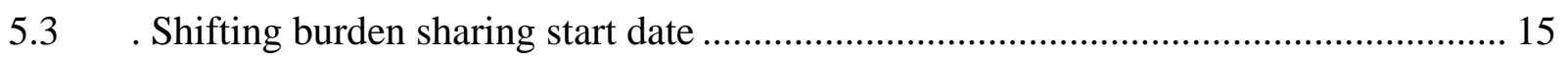

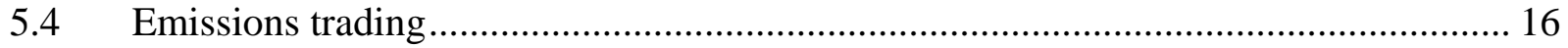

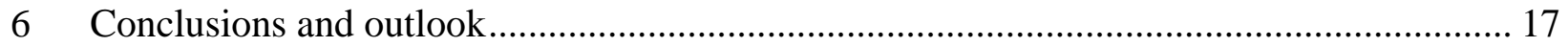

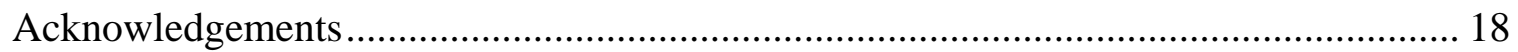

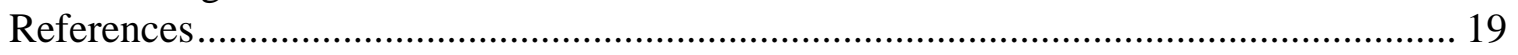

Appendix A. Summary of COBRA-model assumptions and constraints ....................... 21

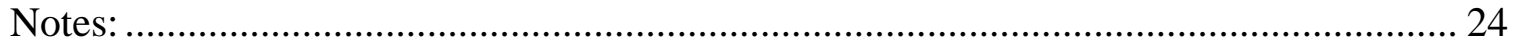




\section{Introduction}

The impact of carbon dioxide $\left(\mathrm{CO}_{2}\right)$ on the world's climate system and the assessment of ways to curb anthropogenic emissions of $\mathrm{CO}_{2}$ have been dominating much of the recent energy debate. It has become increasingly evident that increased concentrations of $\mathrm{CO}_{2}$ intensify the greenhouse effect and thus lead to a gradual warming of the atmosphere. ${ }^{1}$ Scientists expect that this warming will entail—in the medium and long term—consequences for weather patterns on a global, regional and local scale: a rise in global sea level and an increased probability for extreme weather conditions such as storms, floods and droughts are among the phenomena that are predicted by studies reviewed by the Intergovernmental Panel on Climate Change (IPCC, 2001a).

Anthropogenic greenhouse gas (GHG) emissions are related to an increase in average global temperatures through a chain of causal links, and it is possible to estimate the effects of today's emissions on the future climate: what we emit today will affect concentration levels and therefore also future temperature trends, though the entire impact of emissions will only be seen over an extended period of time. Consumption of fossil fuels is the main contributor to global $\mathrm{CO}_{2}$ emissions, so that one of the key questions in mitigating climate change is how the future global energy demand can be satisfied in view of the "ultimate objective" of the United Nations Framework Convention on Climate Change, namely the "stabilization of greenhouse gas concentrations in the atmosphere at a level that would prevent dangerous anthropogenic interference with the climate system" (UNFCCC, 1992). The concentration ceiling is unspecified by the UNFCCC and in view of potential non-linearities and irreversibilities it is unclear where such a level lies (see e.g., Azar and Rohde, 1997). However, for this study we assume an upper concentration limit of 550 ppmv for the year 2100 and beyond, which is about twice the preindustrial level, emphasizing that the target concentration is an adjustable parameter of the model.

How the world's hunger for energy can be satisfied cost-effectively while at the same time staying within the bounds of the concentration ceiling can be assessed with the help of scenarios that enable us to project future economic development and corresponding $\mathrm{CO}_{2}$ emissions. Due to slow responses in the climate system it is necessary to consider long timeframes and to tailor short and medium term mitigation targets in view of long-term stabilization targets. The involvement of non-Annex I countries will be an important factor in the post-Kyoto regime. Thus, in addition to energy supply options and cost-effectiveness, aspects such as international burden sharing (or global permit allocation)² become important as well.

Researchers are investigating three interrelated sets of questions: (1) Can global $\mathrm{CO}_{2}$ emissions be mitigated cost-effectively in the medium and long run? (2) What other schemes exist beyond Kyoto to allocate emission permits globally? (3) What are the implications of these schemes, what are their dynamics, and what are their limitations? (Van Vuuren et al., 2003).

The purpose of this paper is to illustrate one such allocation scheme, discuss its implications for emissions by region, test its limitations, and assess the sensitivity of results to changes in key assumptions. While some aspects of this scheme are similar to the original proposal by Brazil (FCCC/AGBM/1997/MISC.1/Add.3), which proposed a methodology for estimating Annex I 
parties contributions to temperature increases, our approach differs in scope since it focuses on contributions to global cumulative emissions from all regions.

For this purpose we developed a simplified global energy supply and carbon cycle model, the Cost-Optimized Burden-Sharing and Regional emission Allocation in the Energy sector (COBRA-Energy). It is driven by exogenous energy demand projections taken from the SRES (IPCC, 1999), and implements a scheme for international burden sharing for the 21st century, which takes into account the regional amounts of cumulative, anthropogenic emissions. COBRA-Energy was specifically developed to find cost-effective energy supply scenarios that take into account regional permit allocation schemes. ${ }^{\underline{3}}$

COBRA-Energy minimizes the global energy supply costs under a number of economic and technological constraints, which we introduce in the following sections. In the two sectors, electricity production and all direct energy use, a variety of fuel types and technologies are available. The linear structure of the model allows us to build a moderately detailed setting without drawing upon advanced numerical techniques and high power computing.

Models that impose long term cost minimization on stabilization scenarios were developed previously (see e.g., IPCC (2001b), Chapter 8). Our model is different from these in that it also includes a burden sharing allocation of emission permits. The introduction of this permit allocation scheme changes the fuel mix in the energy sector of some regions significantly. Our results suggest that, in terms of energy costs, the SRES region ALM (Africa, Latin America, Middle East) would profit most from this burden-sharing scheme, while the SRES ASIA region (Centrally Planned Asia, South Asia, Other Pacific Asia) ${ }^{4}$ the burden sharing solution offers no significant advantages over the globally cost-optimised solution without regional allocation of emission caps.

The burden sharing takes into account regional shares in cumulative emissions. Historic $\mathrm{CO}_{2}$ emission data are available for as far back as 1750 (see Marland et al., 2003) while future emission data are calculated from the fuel mix that is generated by the model from a given SRES energy demand projection. Other, technology-specific and projected data that are used in the model were taken from standard sources, such as UNDP (2000), IEA (2000), and EIA (2002). Emissions from the land use/land-use change and forestry sector (LU/LUCF) are assumed to follow those of the AIM A1B scenario.

The plan of this paper is as follows. In the next section we discuss the general methodology and describe various aspects of the model. It is followed by a discussion of the baseline, least cost stabilization and burden-sharing scenarios before we comment on the sensitivity of our results to changes in the assumptions. We conclude with an outlook on how the present analysis could be extended. An account of the specific details of the assumptions and the qualitative and quantitative model constraints is given in an Appendix A.

\section{Methodology and model approach}

The results we are presenting here were obtained with the help of COBRA-Energy, a global energy supply model that generates least cost energy supply scenarios in which a projected 
global energy demand for the period 2000-2100 is met with (projected) available resources. The model minimizes a linear function of the cost of energy supply subject to linear constraints on energy demand and energy supply resources.

For the analysis of stabilization scenarios, it includes a fixed $\mathrm{CO}_{2}$ concentration target that is not to be exceeded in 2100, i.e., carbon emissions that are implied by the consumption of various fossil fuels result in concentration levels equal or lower than, say, 550 ppmv in 2100 and beyond. A given concentration target can be reached via different emission paths, and the model finds the least cost path. The burden sharing aspect is implemented by requiring also that regions reduce their emissions relative to the baseline emissions according to their contribution to the total of historic emissions. We will discuss these items in more detail below.

On the one hand, our objective was to build a model that is as realistic as possible under the assumption of linearity. On the other hand, the linear structure of the model does not allow us to model relevant feedback mechanisms. Therefore we have externalised parameters such as cost development including learning curves and retirement rates by assuming exogenously set of learning and retirement rates. $\underline{5}$

The allocation of emission permits for burden sharing is based on past cumulative $\mathrm{CO}_{2}$ emissions and future baseline emissions and proceeds in four steps: (1) the global reduction target at each point in time is calculated as the difference between the annual emissions in the global baseline and in the global stabilization scenario. (2) For each region its share in the cumulative emissions since 1900 up to this point in time is calculated (as a percentage). (3) This percentage is used to assign each region its share in the global reduction target, and to calculate the absolute amount that needs to be reduced in each region. (4) The regional emissions cap is calculated by subtracting this regional reduction target from the regional baseline emissions.

In particular, this means that the amount of permits in each region changes over time for two different but related reasons: first, each region's relative contribution to global cumulative emissions change over time (as recent emissions are added), and second, an absolute global reduction target relative to the baseline is calculated, which may be different in each commitment period.

In the model the world consists of the four SRES regions OECD90, REF, ASIA and ALM, an extension to include, for instance the USA, China and India as separate regions could be developed. We distinguish energy demand in the electricity sector and demand in all other sectors (the 'non-electric' sector). IPCC SRES disaggregates coal, oil, natural gas, nuclear power and biomass fuels (IPCC, 1999); in addition, we include electricity generation from hydroelectric power plants, wind and solar sources. "Solar" also includes geothermal sources. We also distinguish gasoline and diesel from other oil products, though currently transportation is not treated as a separate sector. Table 1 summarizes the fuel options available in the model. 
Table 1. Fuel types in the two sectors of COBRA-Energy

\begin{tabular}{|l|l|l|l|l|l|l|l|l|l|l|}
\hline & Coal & Oil & Gasoline & Diesel & $\begin{array}{l}\text { Nat. } \\
\text { Gas }\end{array}$ & Nuclear & Hydro & Biomass & Wind & “Solar” \\
\hline $\begin{array}{l}\text { Electricity } \\
\text { Production }\end{array}$ & $\mathrm{X}$ & $\mathrm{X}$ & & & $\mathrm{X}$ & $\mathrm{X}$ & $\mathrm{X}$ & $\mathrm{X}$ & $\mathrm{X}$ & $\mathrm{X}$ \\
\hline Other Energy Uses & $\mathrm{X}$ & $\mathrm{X}$ & $\mathrm{X}$ & $\mathrm{X}$ & $\mathrm{X}$ & & & $\mathrm{X}$ & & \\
\hline
\end{tabular}

Energy demand provides the driving force in COBRA-Energy, and demand projections for the model are taken from the AIM A1B scenario as outlined in the SRES, though other scenarios could have been used equally well for benchmarking. Scenarios of the A1 family are based on the assumption of increasing cultural and social interactions, resulting in a reduction of regional differences in per capita income that is mediated, inter alia, by capacity building policies. In A1 scenarios we observe a world of rapid economic growth, low population growth and rapid introduction of new and more efficient technologies.

As was mentioned above, one of the key constraints is the $\mathrm{CO}_{2}$ concentration target for the year 2100. Moreover, the stabilization requirement commits us to scenarios in which the concentration curve has almost a zero slope by 2100 and beyond. Therefore, our model starts in the year 2000 and runs in discrete 10-year steps until the year 2180 to ensure that concentrations do not increase over an extended period of time after 2100. The carbon cycle model we use has previously been employed during the UNFCCC assessment of scientific and methodological aspects of the proposal by Brazil (see UNFCCC, 2002).

Least cost burden sharing scenarios are obtained by following three consecutive steps:

- First, a benchmark is established using the energy demand and fuel use data of the AIM A1B baseline scenario. The total energy demand is already fixed by the AIM A1B scenario data, but our benchmarking establishes a distribution of fuels within the electric and non-electric sectors. It also gives us opportunity to test whether our assumptions about the cost structure and improvements in conversion efficiencies are compatible with the AIM projections.

It is known that the $\mathrm{CO}_{2}$ emissions in AIM A1B scenario imply a $\mathrm{CO}_{2}$ concentration level of around 630 ppmv, well above 550 ppmv by 2100 and, more importantly in the present context, the concentrations follow a curve with positive slope in 2100, meaning that they do not stabilize by 2100 in this scenario.

- In a second step we relax the fuel use constraints and calculate a least cost stabilization scenario that matches the same projected energy demand, both for electricity and non-electric energy uses, and the $\mathrm{CO}_{2}$ concentration is stabilized at $550 \mathrm{ppmv}$ by 2100 . The global $\mathrm{CO}_{2}$ emissions in this scenario are shown in Fig. 1. The least cost stabilization solution provides us with regional fuel mix data for electricity generation and all other energy uses. From these fuel mixes we calculate the implied emission profiles and the concentration curve for the period 2000-2180. A comparison of the fuel mixes for the least cost stabilization and the benchmark scenarios, details of which can be found in Sathaye and Wagner (2003), indicate how individual 
regional fuel mixes and emission profiles change in a cost-effective stabilization with respect to the benchmark. One can also compare the corresponding carbon intensities (mass of carbon per unit of energy) and can derive regional targets for the intensities in the stabilization scenario. Finally, regional and global cumulative energy costs are obtained for the stabilization scenario.

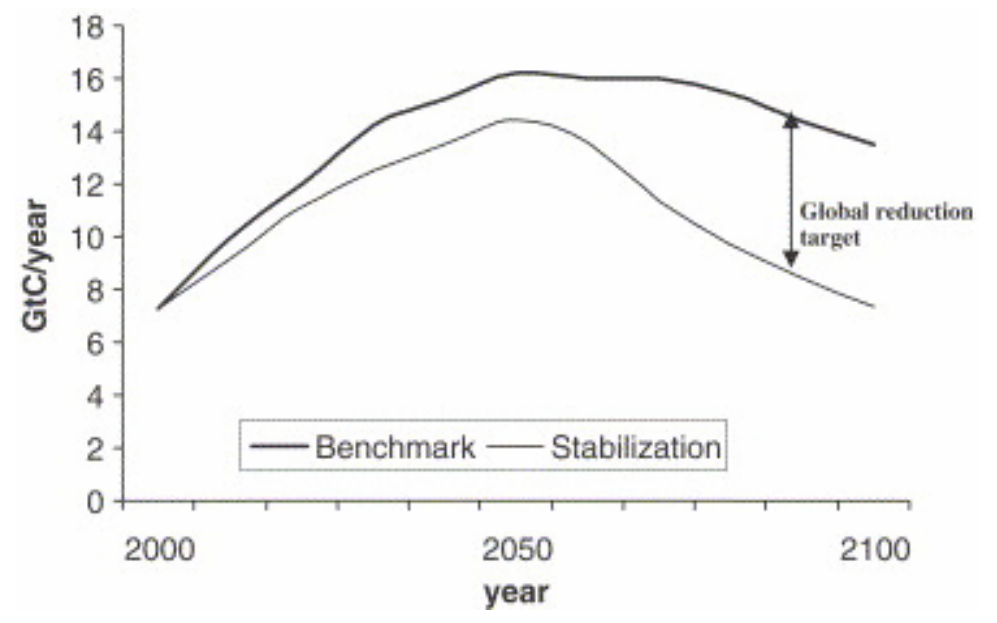

Fig. 1. Global emissions baseline and the least cost stabilization scenario emissions (550 ppmv in 2100) (discount rate—4 percent).

- The third step of our approach is to calculate a burden-sharing scenario in which regional emission caps are imposed. Burden sharing is based on a version of the "polluter pays" principle, to be discussed shortly. This scenario minimizes the costs under the additional constraint that regional emission caps are not to be exceeded. This least cost burden-sharing scenario-like the least cost stabilization scenario-provides a set of regional fuel mixes in both the electric and other energy use sectors as well as corresponding annual changes in carbon intensities and energy costs.

It is worth noting that the total energy demand remains unchanged in each decade across the three scenarios. The fuel supply mix thus changes in response to stabilization and emissions constraints while meeting the same energy demand in each scenario. Let us now turn to the discussion of the three individual scenarios, starting with the benchmark scenario.

\section{The benchmark scenario}

The first step in our analysis is to test our assumptions about economic mechanisms and cost structure. We calibrate the linear COBRA-Energy model using the AIM A1B scenario described in the SRES (IPCC, 1999). We could have chosen to use a different benchmark scenario, e.g., one which is cost-optimized using the parameters in our model without the stabilization constraint. We chose the A1B scenario since it belongs to the well known IPCC family of scenarios. The difference in emissions and costs between this benchmark and least-cost stabilization scenarios thus may be due to other factors in addition to the carbon concentration constraint. We hence refrain from analyzing the difference in costs between the benchmark and least-cost stabilization scenarios. The objective in this part of our work is to generate a benchmark scenario that reproduces consumption data of the AIM A1B baseline scenario with an 
extended set of fuel types. We obtain the fuel mix data for all four regions in both sectors, which we have described elsewhere in detail (Sathaye and Wagner, 2003).

In the benchmark scenario, the $\mathrm{CO}_{2}$ concentration reaches a level of 630 ppmv by the year 2100 with a fairly steep upward trend (Fig. 5). Global cumulative $\mathrm{CO}_{2}$ emissions from fossil fuel burning during the 21st century add up to $1370 \mathrm{Gt}$ C. We note that emissions and concentrations in the benchmark scenario differ slightly from the SRES values due to use of IPCC default values for carbon content parameters and also because under the given set of constraints the activity data cannot be reproduced exactly. However, in the present context the differences are minor. Regionally, emissions increase slightly in OECD90 and REF before starting a slow long decline while those in the other two regions increase until about 2070 before declining (Fig. 2).

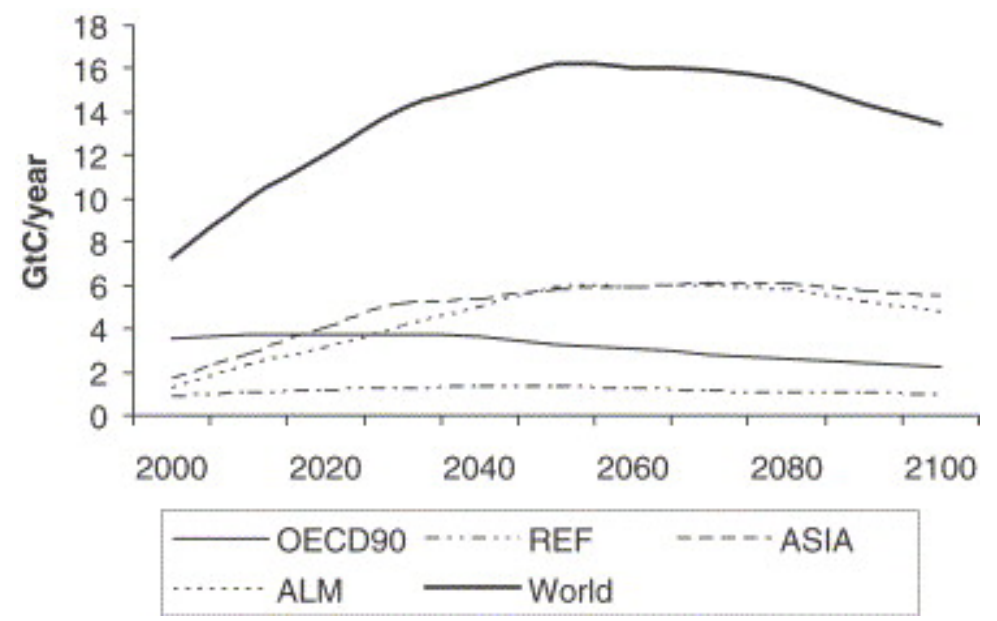

Fig. 2. Global annual $\mathrm{CO}_{2}$ Emissions in the AIM A1B benchmark scenario.

\subsection{The least cost stabilization scenario}

Having established a benchmark, we move on to stabilization scenarios. In the least cost stabilization scenario exogenous energy demand data are again taken from the AIM reference scenario and $\mathrm{CO}_{2}$ concentrations are stabilized at or below 550 ppmv by the year 2100 (Fig. 5) and maintained below this level until the year 2200. In order to meet this target global emissions are reduced in a cost-effective manner. The global cumulative emissions from fossil fuel burning during the 21st century in this scenario add up to $1110 \mathrm{Gt} C$ or about $19 \%$ less than in the benchmark scenario. In the following we compare emission levels in the stabilization scenario with the benchmark scenario which was obtained using the same methodology. The burden sharing scenario then uses the same parameter values and emissions reduction in each decade, while adding the burden sharing requirements to the stabilization scenario.

In the stabilization scenario global emissions are always lower than the benchmark, and we observe a rapid decrease in the second half of the century, while in the early part of the century global emissions departures from the global benchmark emissions occur only gradually (Fig. 1 above) (cf. also IPCC (2001b), Section 8.4.2.). In Fig. 3 the increasing global emissions reduction target (difference between the benchmark and least-cost stabilization scenario) until 2100 is shown. 


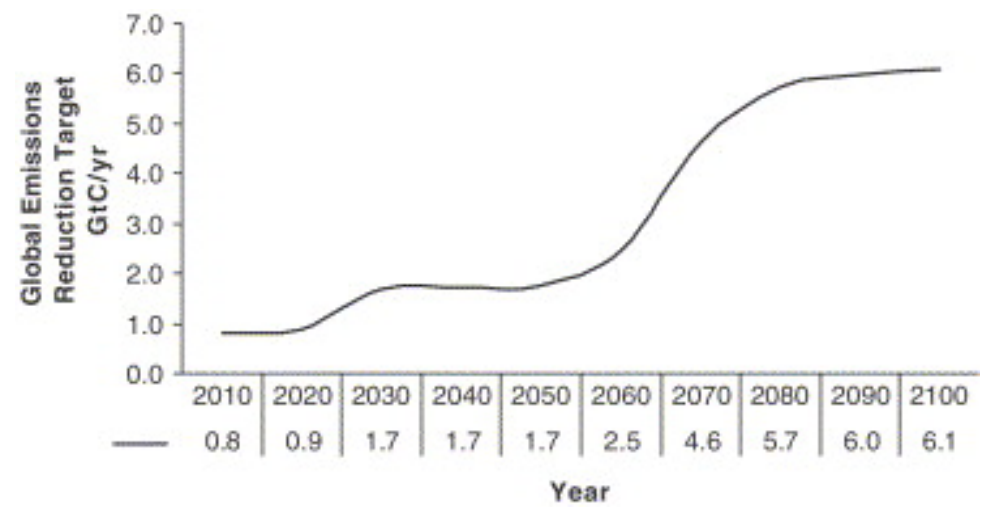

Fig. 3. Global emissions reduction target relative to the benchmark scenario as a function of time.

Fig. 4 shows the emission profile in this stabilization scenario; global emissions decline to about the 2000 levels $(7.4 \mathrm{Gt} \mathrm{C/yr}$ ), and correspondingly there is a steady increase in emissions for the ASIA and ALM regions until the year 2050, while OECD90 emissions already peak around the year 2030.

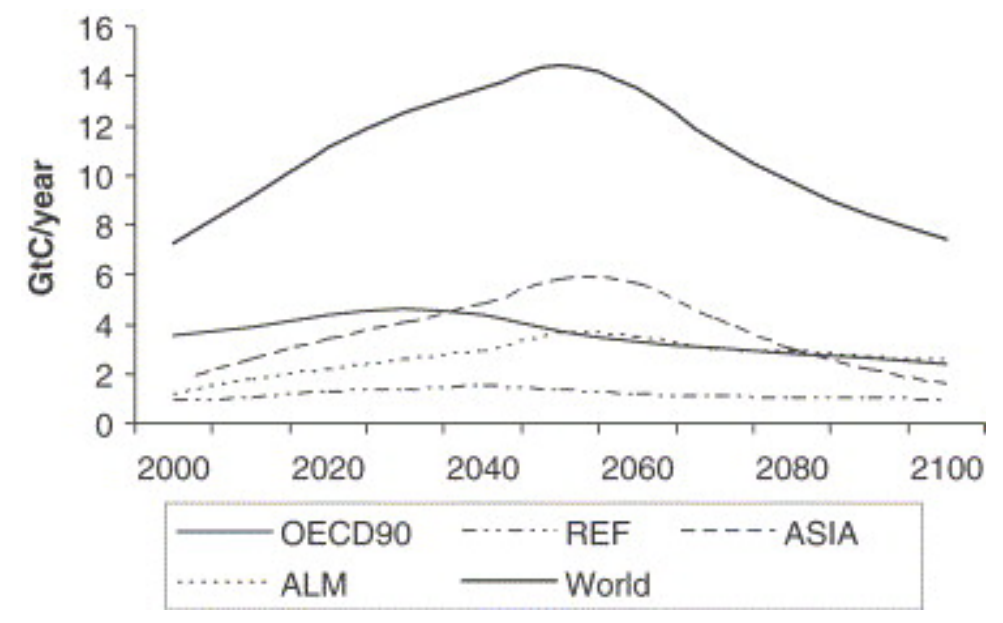

Fig. 4. Regional $\mathrm{CO}_{2}$ emissions in the least cost stabilization scenario (cf. also Fig. 1).

A few observations regarding the regional fuel mixes may be made here (for details, see Sathaye and Wagner, 2003). In the ASIA region we observe a fairly sharp decrease in emissions between 2050 and 2070 when in the electricity sector coal is largely replaced by solar and wind energy. Compared to the benchmark scenario we observe an increased use of coal in all regions, in particular in the first half of the century, owing to the fact that it is the cheapest fuel available in the scenarios. On the other hand more costly oil products in the non-electric sector are significantly reduced in favor of biofuels (all regions) and natural gas (OECD90). We also observe more hydroelectric power being used in the ASIA and ALM regions than in the benchmark scenario, whereas natural gas is being used less in these regions. 


\section{The burden sharing scenario}

Since the burden sharing procedure is central for our analysis, let us first discuss it in more detail. We have mentioned earlier that the benchmark emissions lead to $\mathrm{CO}_{2}$ concentration levels that lie above the target of $550 \mathrm{ppmv}$ in 2100 (and beyond). In order to reach the stabilization target it is therefore necessary to reduce global annual emissions, and the least cost solution provides the most cost-effective solution for doing so. By comparing the least cost solution with the benchmark emissions one can calculate for each point in time by how much global emissions need to be reduced (relative to the benchmark) in order to reach the target concentration by 2100 (see Fig. 1). How these emissions reductions are to be assigned to the regions or individual countries is determined with the help of a burden sharing prescription.

Basis of the burden sharing prescription that is used in this paper is the understanding that a region's share in the world's effort to curb $\mathrm{CO}_{2}$ emissions should be proportional to its share in past cumulative global emissions. In plain English, the more you have emitted in the past, the more you have to reduce in the near future.

A simple example will illustrate the point, and for the sake of the argument assume that the Kyoto Protocol was not in place and that the burden sharing started in the year 2010. The global emissions of our benchmark scenario in the year 2000 are $7.3 \mathrm{Gt}$ C/yr, for 2010 the corresponding value is $9.9 \mathrm{Gt} \mathrm{C} / \mathrm{yr}$. The emission path that achieves $\mathrm{CO}_{2}$ concentration stabilization in 2100 most cost-effectively (see Fig. 1) prescribes an emission level of $9.1 \mathrm{Gt} \mathrm{C/yr}$ in 2010. Thus, in 2010 the global reduction target relative to the benchmark is $0.8 \mathrm{Gt} \mathrm{C/yr.} \mathrm{This}$ is distributed among the four regions as follows: for instance, in the year 2000 the OECD90 region had contributed about 56 percent of past global cumulative emissions of $\mathrm{CO}_{2}$ from fossil fuel combustion. Therefore, they reduce $0.44 \mathrm{Gt} \mathrm{C} / \mathrm{yr}$, i.e., 56 percent of $0.8 \mathrm{Gt} \mathrm{C}$, from their benchmark value in 2010, which is $3.77 \mathrm{Gt} \mathrm{C} / \mathrm{yr}$. Thus, the emission cap for the OECD90 region in 2010 is calculated at 3.77-0.44 Gt C/yr=3.33 Gt C/yr. Relative to the 2000 emission level of $3.56 \mathrm{Gt} \mathrm{C} / \mathrm{yr}$, this corresponds to an emission reduction of 6.5 percent between 2000 and 2010.

Note that, since each region now will have an emission target for 2010 that differs from the benchmark (e.g., $3.33 \mathrm{Gt}$ C/yr vs. $3.77 \mathrm{Gt}$ C/yr), the cumulative emissions in 2010 will be different from those in the benchmark. In particular, in regions with low emissions during the 20th century the difference can be substantial, since the late and high emissions tend to contribute a larger proportion to cumulative emissions. As a consequence, each region's share in the global cumulative emission in 2010 will to some extent depend on how much emissions were reduced between 2000 and 2010. If a region has reduced more than others, its share will typically decrease; conversely, if a region reduces less than others, its share in cumulative emissions will increase. Thus, this burden sharing prescription reveals an interesting dynamics: early action is rewarded, since it reduces a region's future share in the effort to mitigate emissions; and as a consequence, all else being equal, there is a natural competition between regions to reduce emissions faster than others. The regions' shares in cumulative emissions since 1900 carry substantial inertia and do not change very quickly over the 21st century, whereas if only the emissions of the past, say, 30 or 40 years were counted, the shares of the regions could change more rapidly. This would increase the incentive for reducing emissions earlier (Fig. 5). 


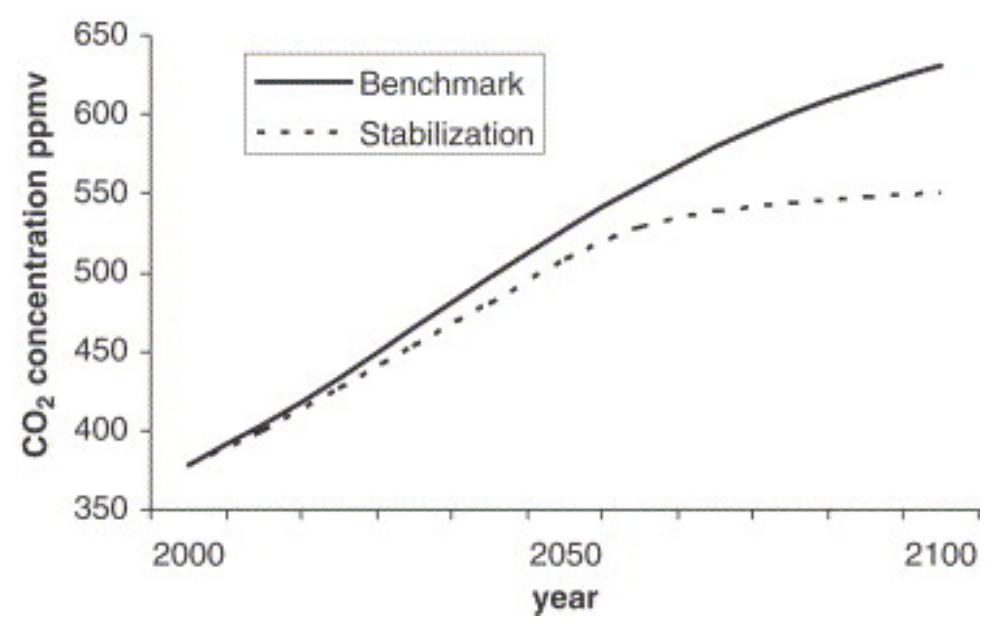

Fig. 5. $\mathrm{CO}_{2}$ concentration levels for the benchmark and the stabilization scenario.

Note also that, at this stage of our modelling exercise we assume immediate participation of all world regions in the burden-sharing scheme. More realistically, when more than four regions are considered, criteria for participation would be considered, e.g., a lower bound on GDP per capita, etc., or a delay in the global application (see below).

Before we move on, let us make a remark concerning the method of calculating regional shares in the global reduction target. In order to calculate each region's share we consider historic emissions and simply add all emissions from the year 1900 until the time of interest with equal weight. Alternatively, one could estimate a region's share in the concentration increase (compared to pre-industrial levels). For this one would have to take into account that only a fraction of the $\mathrm{CO}_{2}$ emitted in, say, 1900 is still present in the atmosphere and contributes to an increased concentration, but for the purpose of this paper we restrict ourselves to a burden sharing prescription that weighs emissions independently of where or when they have occurred. $\underline{6}$

We now turn to the discussion of the burden-sharing scenario. First we need to mention that in view of the timeframe of the Kyoto protocol we impose the burden sharing prescription only in and after the year 2020. In Fig. 6, we have summarized the regional emission data of the benchmark, least-cost stabilization and the burden sharing scenarios. In the ALM region the burden sharing emissions lie consistently higher than the least cost emissions, while for OECD90 and REF the opposite is true. (For ASIA the least cost and burden sharing profiles are very similar in the first half of the century.) This supports the expectation that in the least cost solution emission reductions are mostly cheaper achieved in developing countries, while the more equitable burden sharing causes a shift of these reductions towards developed countries. 

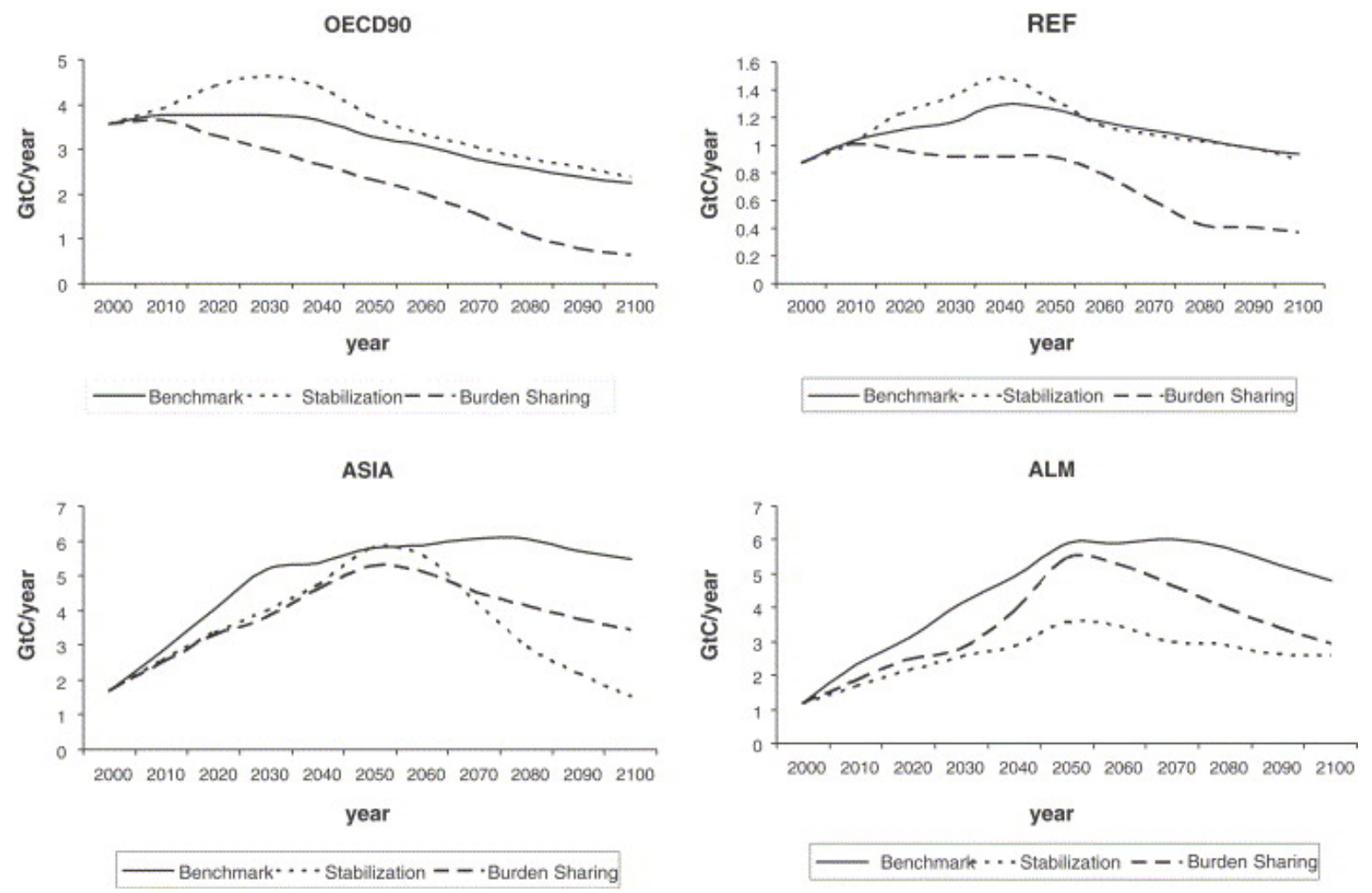

Fig. 6. Comparison of regional $\mathrm{CO}_{2}$ emission paths in the benchmark, least cost stabilization and the least cost burden sharing scenarios.

Let us now look at the resulting emission permit allocation at a higher level of aggregation, namely for the Annex I and Non-Annex I regions, ${ }^{\underline{7}}$ and compare the figures with the allocation in the least-cost solution without burden sharing (Fig. 7).

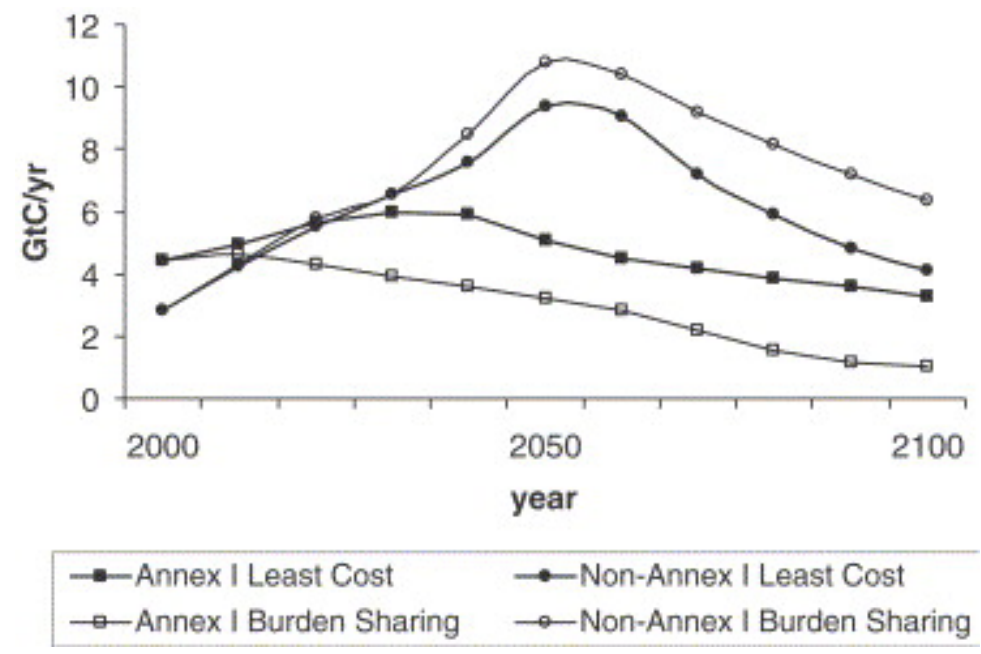

Fig. 7. Comparison of annual Annex I and Non-Annex I $\mathrm{CO}_{2}$ emission permit allocation with and without burden sharing. 
As expected, it can be seen that in the burden-sharing scenario the Annex I regions have to reduce their emissions earlier and faster than in the least cost scenario. Note that in the burden sharing scenario non-Annex I emissions will exceed Annex I emissions much earlier than in the least cost scenario (in 2015 compared to 2025). ${ }^{-}$Note also that, while in the least cost scenario the Annex I region sees an increase in emissions of 11 percent between 2000 and 2010, the burden sharing - even though imposed later-entails an increase of only 5 percent over the same period. Thus, even though they are not forced to, the Annex I region reduces emissions already by 2010, anticipating strict targets by 2020. Early action pays in this case not only because it helps achieving long term targets, but also because early action lowers the relative share in cumulative emissions early, leading to less stringent targets in the future, as explained above. By the year 2100 Annex I has reached an emission level of about $1.0 \mathrm{Gt} \mathrm{C/yr} \mathrm{in} \mathrm{the} \mathrm{burden} \mathrm{sharing}$ scenario, i.e., 30\% compared to the least cost solution at the same point in time and approximately only one-quarter of Annex I emission level in 2000.

Fig. 8 illustrates how the shares in cumulative emissions change dynamically as a consequence of the mechanism described above. The difference is particularly pronounced for the OECD90 and the ALM regions. By the year 2100 the non-Annex I region's share in the cumulative emissions $1900-2100$ is 51\% (stabilization without burden sharing) and 65\% (stabilization with burden sharing), respectively.

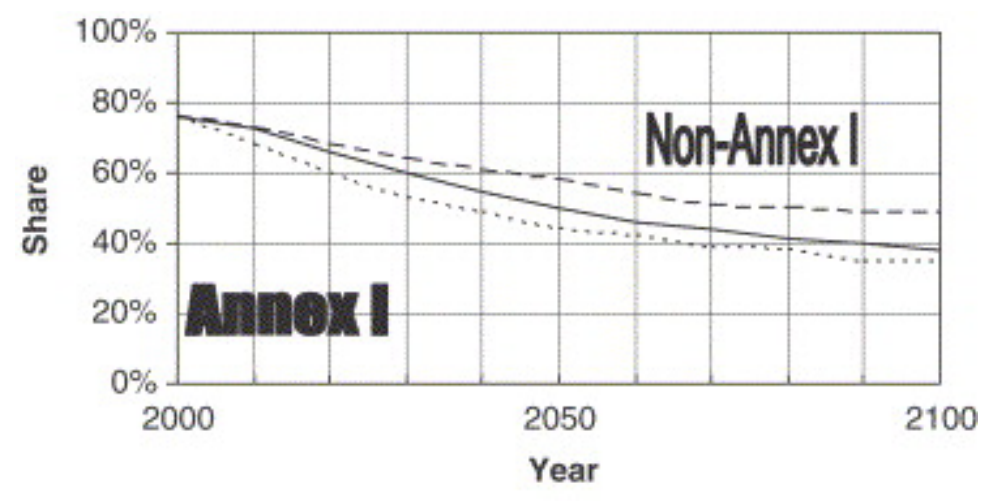

Benchmark---- Stabilization....... Burden Sharing

Fig. 8. Relative shares of the SRES regions in the cumulative emissions from fossil fuels since 1900.

The burden sharing prescription can be thought of as yet another constraint in addition to the constraints considered in the stabilization scenario, such as the stabilization of the concentration itself, but also energy demand, fuel resources, etc. How does this additional burden sharing constraint affect costs, globally and regionally? Fig. 9 shows the additional cost in the scenario with burden sharing compared to the stabilization scenario without burden sharing. 


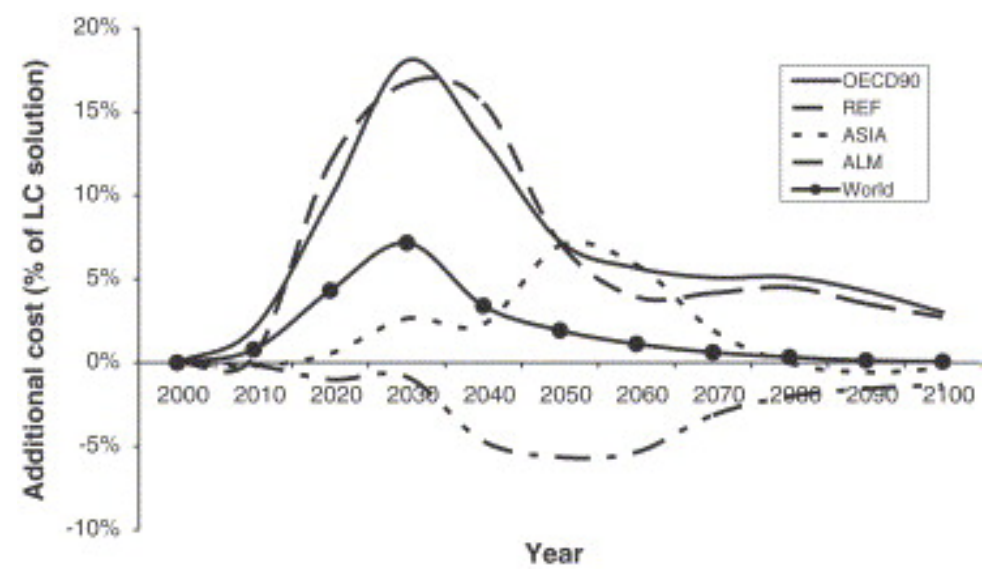

Fig. 9. Change in energy cost in the burden sharing scenario compared to the least cost stabilization scenario. (For example, in ALM the energy supply cost during the year 2050 is about 6 percent lower in the burden sharing scenario compared to the least cost stabilization scenario.)

We note that while ALM clearly benefits in the burden-sharing regime (in ALM the burden sharing solution is always cheaper than the global least cost solution), for ASIA the burdensharing scenario is generally slightly more expensive. This can be explained as follows. In the burden sharing scenario ASIA uses less coal for electricity production and more hydro and biomass than in the least cost stabilization scenario, which are more expensive than coal. There is more coal used in ASIA than in ALM in the least cost stabilization case, because we have assumed that, among the four regions, coal is cheapest in the ASIA region. Thus, when emission targets are applied, the ASIA region has to reduce its coal use and increase the use of less carbon intensive, but more expensive fuel, whereas ALM can still increase its coal use (and reduce costs), due to less strict emission targets.

Developing countries generally benefit from the burden sharing, in absolute and relative terms, compared to Annex I countries, since they are allowed to emit more relative to the globally costoptimised solution, in which developing countries contribute more to the global reduction. Conversely, for the OECD90 and REF region the burden sharing solution is consistently more expensive, peaking in 2030 when the burden sharing solution is about $17 \%$ more expensive than the stabilization scenario without burden sharing.

\subsection{International emissions trading}

A scenario that includes a full, unrestricted international emission trading (ET) regime leads back to the least cost solution emission profiles, independently of the carbon price. This is because COBRA-Energy minimizes a global cost function, and the net global revenue from carbon trading is zero. Thus, emissions are reduced in the globally optimal way, and trading flows reflect the allocation of emissions. In a trading regime, the amount of carbon traded by each region is exactly the difference between the regional least cost emission profile and the regional burden sharing profile. 
As we explain in Appendix A, the model restricts the transition to less carbon-intensive fuels by assuming a maximum decommissioning rate of 30 percent of each fuel use over 10 years: for example, in 2060 a region's use of coal cannot be less than 70 percent of its coal use in 2050. This puts a constraint on the ability to reduce emissions rapidly, and the feasibility of a given emission target.

In the model, if a region $\mathrm{A}$ is unable to reach its assigned share of reductions, then the other three regions have to share the difference in emissions between the target set for $\mathrm{A}$ and what is feasible for A. This difference is distributed amongst the other regions, and again the cumulative emissions are used as the distribution key. ${ }^{-}$In fact, in the scenario we have presented some of the reductions initially assigned to OECD90 indeed have to be achieved in REF, ASIA and ALM, because the OECD90 region cannot reduce emissions quickly enough to meet the target. For instance, in 2080 the difference between the prescribed reduction and the feasible reduction for OECD90 together amounts to $0.21 \mathrm{Gt} \mathrm{C} / \mathrm{yr}$, and is distributed among the REF, ASIA and ALM region—according to the burden sharing agreement between them.

This additional or second-order burden sharing can be interpreted as a lower bound on the volume of internationally traded emissions: the OECD90 reduction target cannot be reached in this region alone and so permits need to be bought from the other regions, cf. Fig. 10. This method of reassigning emissions fails, however, if the additional emission reduction implies that one of the receiving regions cannot meet its new target due to economic constraints.

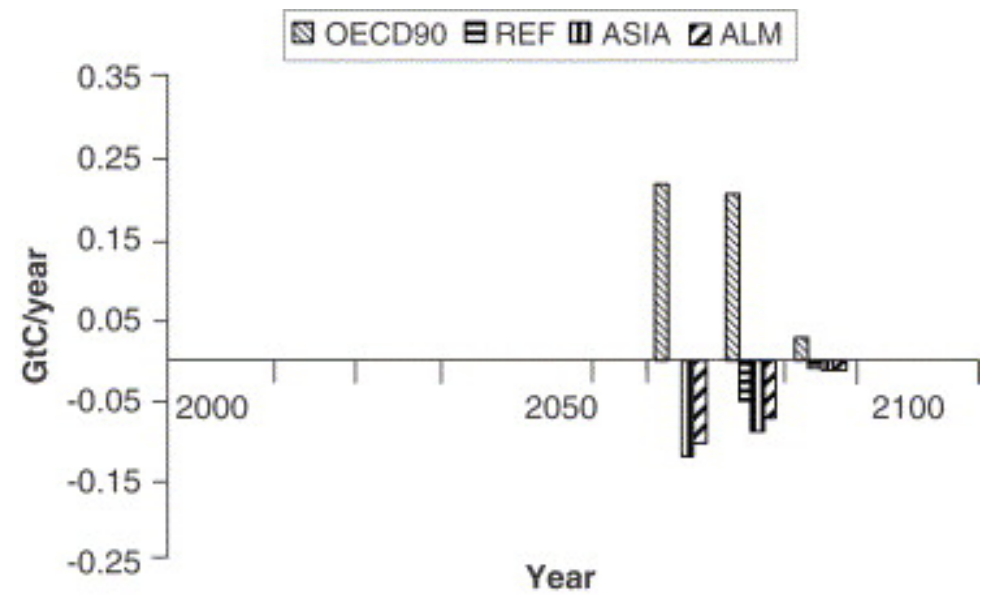

Fig. 10. Lower bounds on carbon trading volume in the burden sharing scenario (discount rate4\%) (Positive values=carbon bought, Negative values=carbon sold).

When the revenues from international emissions trading are considered Fig. 10 will change accordingly, and the scale of the relative differences will depend on the carbon price, which in COBRA-Energy is an exogenous parameter, i.e., feedbacks are not represented in this framework. The net cost per ton of $\mathrm{CO}_{2}$ reduced, however, can be calculated and is shown in Fig. 11 for our scenario with a discount rate of 4 percent p.a. 


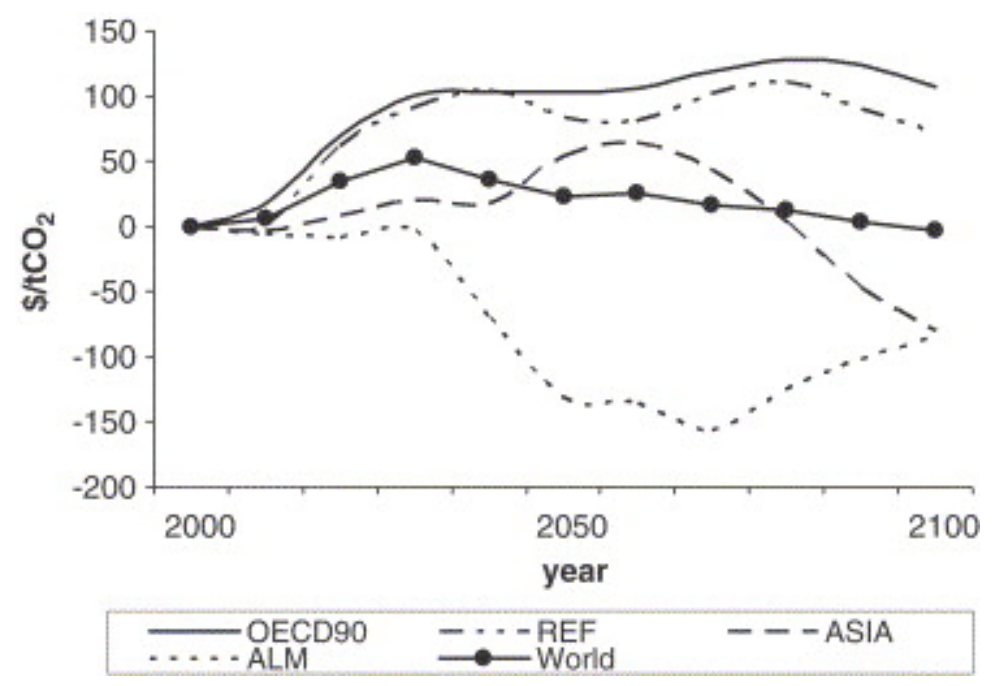

Fig. 11. Net cost per ton of $\mathrm{CO}_{2}$ reduced (discount rate-4\%).

\section{Sensitivity analysis}

In this section we compare the results for scenarios in which some of the key parameters entering the analysis were varied.

\subsection{Concentration target}

In the first place, the choice of a concentration target of 550 ppmv is somewhat arbitrary and different choices for these parameters can be considered. In Fig. 12 the global emissions reduction target is shown as a function of different concentration targets. In the vicinity of a concentration target of 550 ppmv, relaxing the concentration constraint delays the steep increase in emissions reduction from 2050 onwards by about six years, while with a tighter constraint it yields a solution in which reductions occur correspondingly earlier.

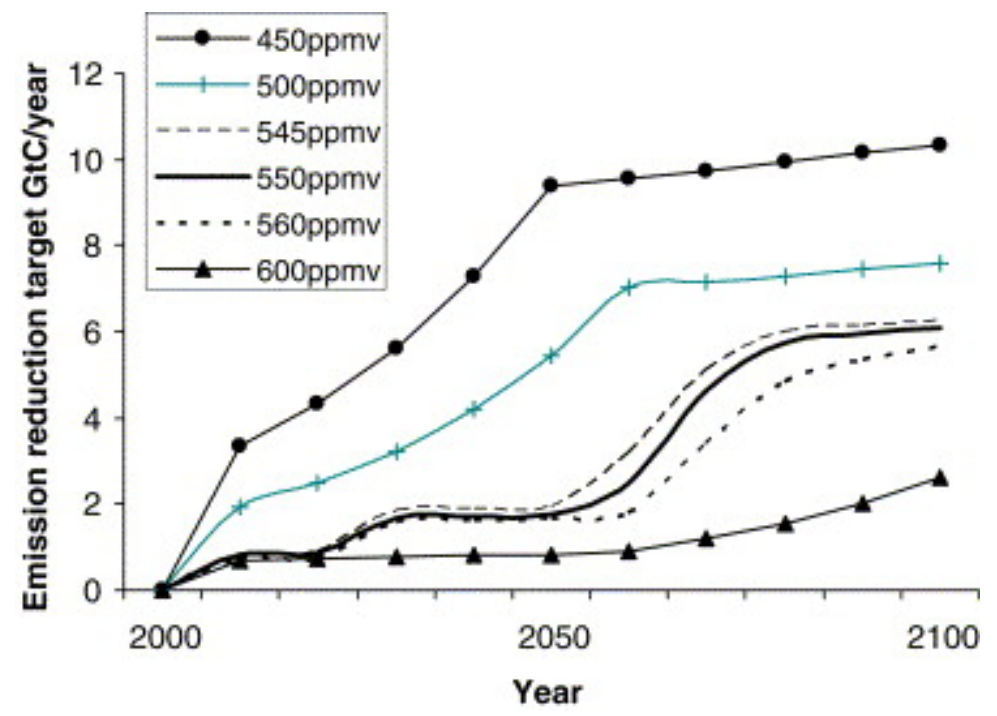


Fig. 12. Global emission reduction targets as a function of the stabilization target.

For significantly different target concentration levels (450 and 600 ppmv) the global reduction targets change accordingly. For reaching the 450ppmv target, higher maximum decommissioning rates, higher stock turnover and higher economic potentials for renewables had to be assumed. Even so, the burden sharing approach discussed in this paper is infeasible for this concentration target, the regional targets derived from the global target cannot be achieved.

\subsection{Discount rate}

The scenario results, such as the least cost global emission profile and regional allocation of emission permits vary mildly with the assumed discount rate. In Fig. 13 the additional global cost of the burden sharing is plotted over time for four different values of the discount rate. One observes that at higher discount rates the additional cost is lower in the first half of the century, because at higher discount rates costly measures are delayed until a later time when they are discounted in the total cost function. Consequently, later in the century the additional cost at higher discount rates is higher than at lower rates.

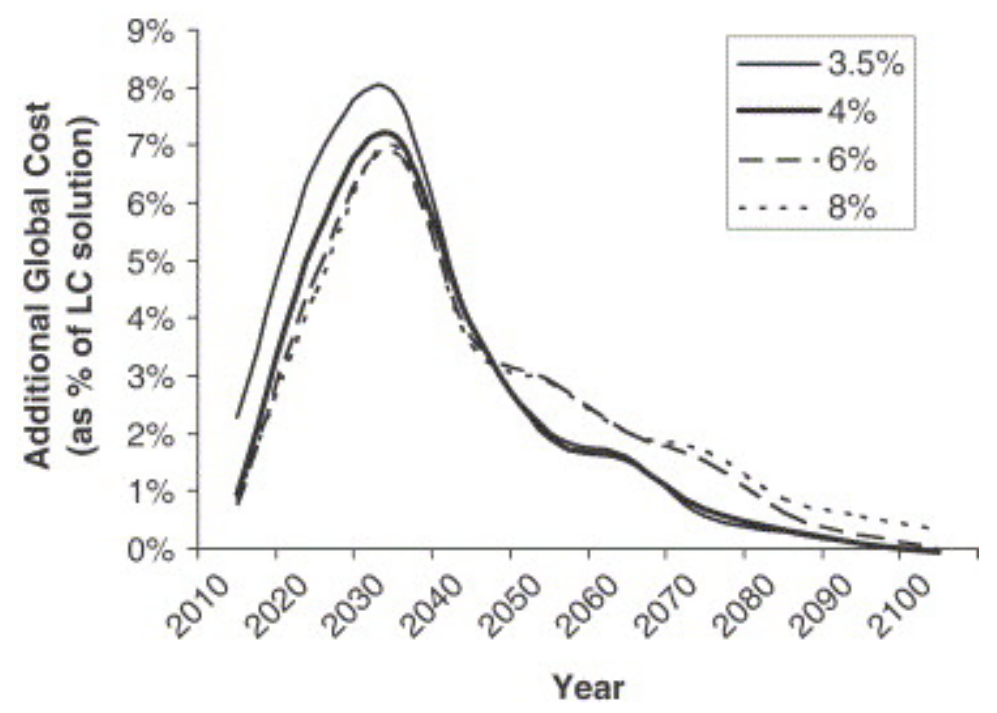

Fig. 13. Additional global cost of the burden sharing scenario relative to the least-cost stabilization scenario as a function of the discount rate.

\subsection{Shifting burden sharing start date}

One can imagine a world in which the burden sharing prescription, as we have described it, would not be applied globally from 2020 onwards, but that other transitory frameworks would apply first, and the burden sharing regime would be entered at a later stage. In Fig. 14 an emission scenario in which the burden sharing regime begins in the year 2050 is compared to the emission profiles of Fig. 6. A delayed reduction effort in the Annex I region can clearly be discerned. For ASIA the emission profile does not depend on whether the burden sharing begins in 2020 or in 2050. 
OECD90

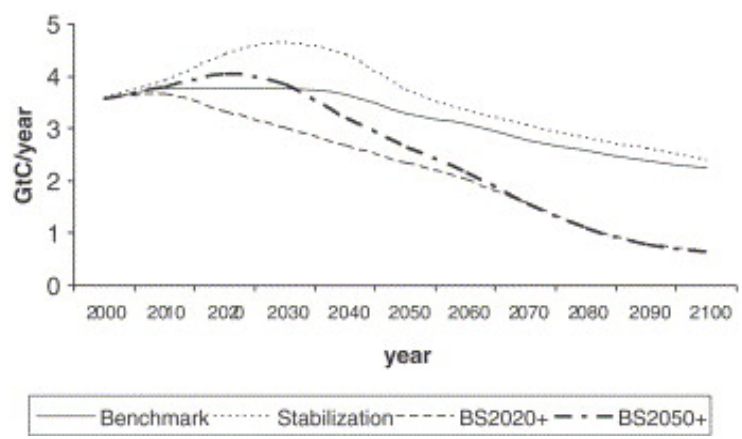

REF

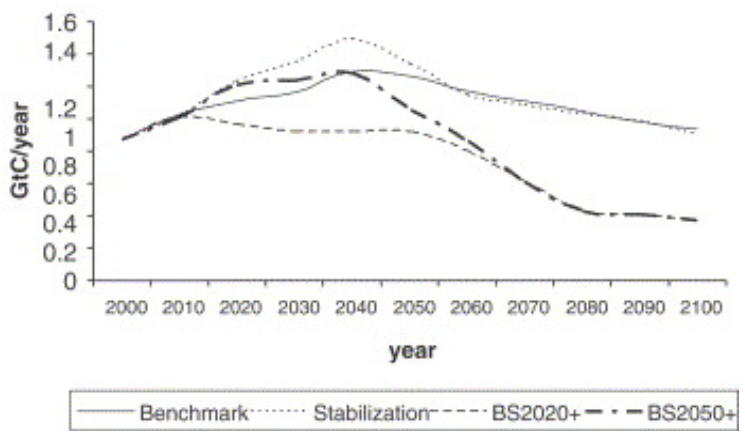

Fig. 14. Regional emission profiles for the benchmark, least-cost stabilization, and two burden sharing scenarios (compared to Fig. 6 the emissions from a burden sharing scenario in which the burden sharing is applied from the year 2050 onwards('BS2050+') were added).

For this 'delayed' burden sharing regime Fig. 15 shows the additional cost relative to the least cost stabilization solution, in which for the Annex I region the additional costs are typically less than in the case where the burden sharing is applied from 2020 onwards, cf. Fig. 9.
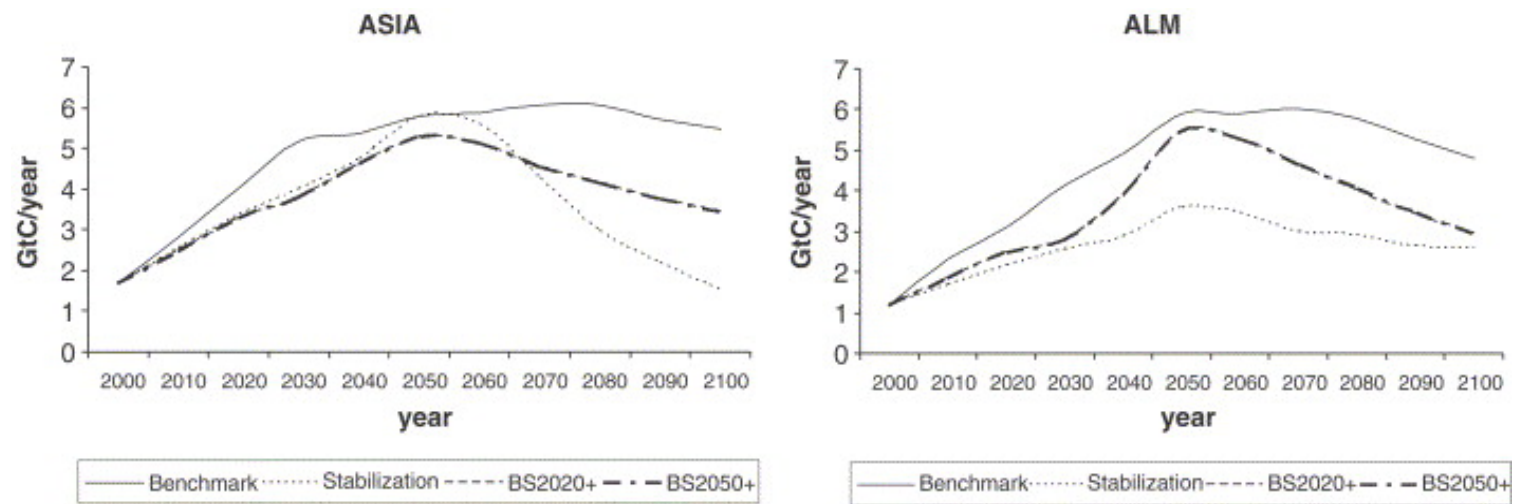

Fig. 15. Change in energy cost in the burden sharing scenario applied from 2050 onwards compared to the least-cost stabilization scenario.

\subsection{Emissions trading}

The volume of emissions under burden sharing depends on a number of factors, in particular the shape of the least cost emission profile, the assumptions on technology decommissioning rates and also the discount rate. For instance, all else being equal, for higher discount rates we observe higher values for such trading volumes (cf. Fig. 16). 


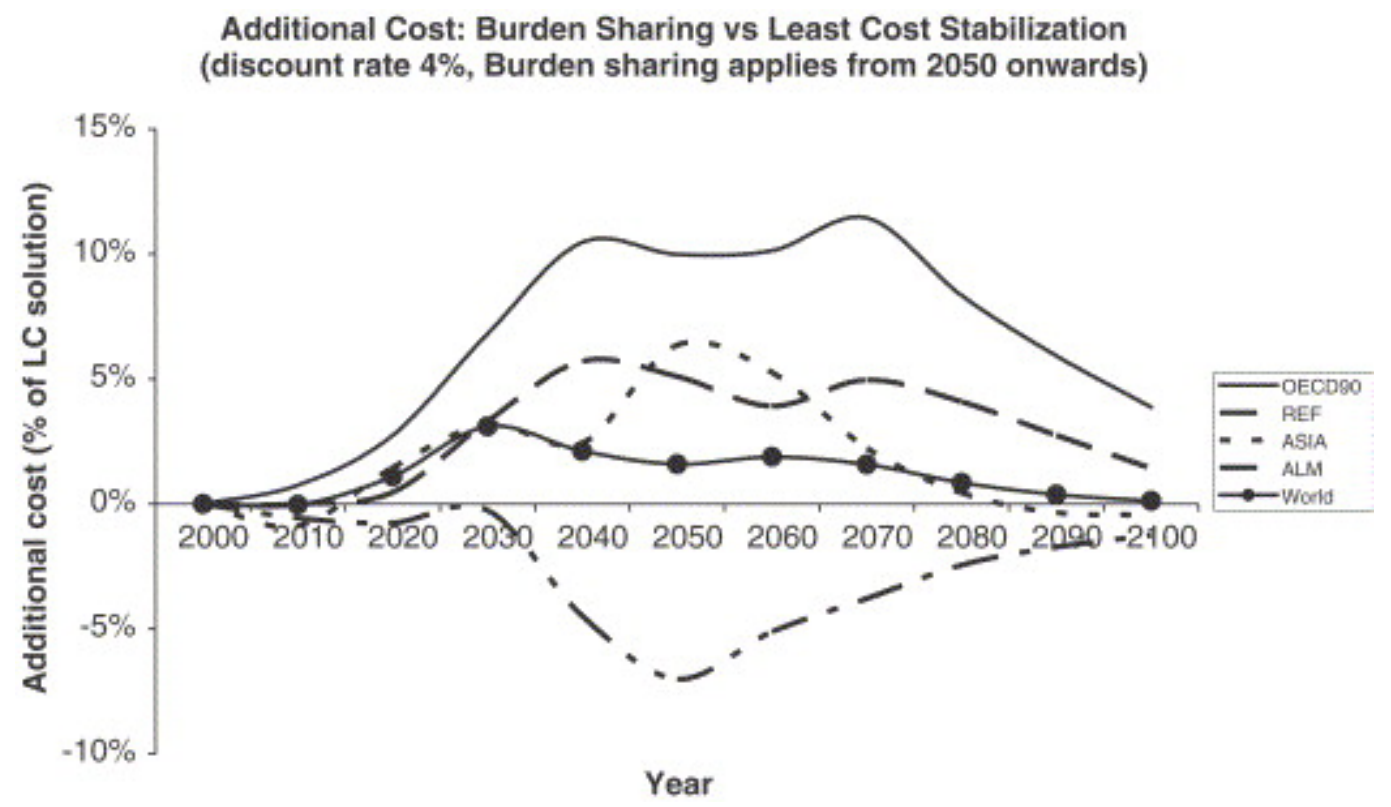

Fig. 16. Lower bounds on carbon trading volume at a discount rate of $8 \%$ (positive value $=$ carbon bought, Negative value= $=$ arbon sold).

This is due to the fact that, for OECD90, the emissions in the benchmark scenario at a discount rate of 8 percent lie slightly higher than for the benchmark scenario at 4 per cent. Since the burden sharing solutions at these two different interest rates do not differ significantly the difference between the benchmark scenario and the burden sharing scenario is larger (in absolute terms), i.e., OECD90 needs to reduce more. Yet, as was explained above, OECD90 cannot reduce more than what is feasible, and so the additional reduction has to be achieved through additional trading than was observed at a 4 percent discount rate.

\section{Conclusions and outlook}

We have used COBRA-Energy to implement a burden sharing prescription into a moderately sophisticated energy supply model. The benchmark scenario matches energy demand and fuel use data of the AIM A1B reference scenario and provides the emission baseline in our analysis. With the assumptions used in this version of COBRA-Energy, the $\mathrm{CO}_{2}$ concentration target of 550 ppmv by the year 2100 is reached at least cost by reductions mostly in the ASIA and ALM regions, while in the burden sharing regime emissions are allocated according to the burden sharing distribution key based on cumulative emissions since 1900.

The prescribed burden sharing reduction targets are too ambitious for the OECD90 (and REF) regions in the later part of the century, however, so that the ASIA and ALM regions take over some additional reduction burden. This secondary burden can be interpreted as a lower bound on the volume of carbon traded.

We have observed an interesting interplay between global and regional perspectives in the scenarios. In the scenario without burden sharing emission reductions occur where they can be achieved cheapest; in the burden sharing regime they are allocated according to past emissions. 
Differences in emissions, especially by the end of the 21st century can be substantial, although the differences in energy costs introduced by the burden sharing are moderate. The average energy cost globally increases in the burden sharing regime, however, that in the ALM region decreases, because this region now uses more coal and less hydro compared to the global stabilization scenario.

Early action pays in this scheme, because it reduces cumulative historical emissions which lightens a region's burden, and thus provides the region a natural incentive to not delay its emissions reductions.

Some of the results we have presented are sensitive to changes in the underlying parameters, and the stabilization scenarios are only feasible if they are consistent with scenario assumptions used for the benchmarking - as could be expected. In the future we would like to extend the analysis to other benchmark scenarios in order to be able to discuss this burden sharing regime in the context of more ambitious stabilization targets.

Simple constraints have been used to implement some economic mechanisms into our linear model in order to model the dynamic fuel consumption pattern over time. Since these constraints play an important role in our qualitative assessment it would be useful to develop them further by taking into account regional economic circumstances in the dynamics. Furthermore the model could be extended to include more geographical regions, noticeably the USA, China and India, as well as an extended set of sectors and technologies. We mentioned in an earlier section to treat the transportation sector separately. Sequestering options and carbon credits from sinks, i.e., individual options for reducing regional net emissions and costs could be included into the model as well. Furthermore, any comprehensive analysis of the climatic implications has to take into account other greenhouse gases (at least methane and nitrous oxide), as well as aerosols.

The environmental cost of $\mathrm{CO}_{2}$ emissions is not taken explicitly into account in our scenarios, although it is implicitly reflected in the stabilization constraint. However, the concentration level may not be a good proxy for damages caused by climate change. The change of the average surface temperature or its rate of change might be better proxies, and constraining one of these could lead to new insights into feasible long term mitigation strategies. This, however, requires a non-linear setting.

\section{Acknowledgements}

For useful discussions we would like to thank Joyashree Roy, Alan Sanstad and Katja Schumacher. F.W. would like to thank the International Energy Studies Group at the Berkeley Lab for kind hospitality and financial support, and the International Climate Policy Group at the Hamburg Institute of International Economics for kind hospitality. The authors are grateful for the insights and guidance provided by two anonymous referees, which significantly improved the analysis and presentation of the paper. This work was supported in part by the US Environmental Protection Agency, Office of Atmospheric Programs, through the US Department of Energy Contract No. DE-AC03-SF00098. 


\section{References}

Azar and Rohde, 1997 C. Azar and H. Rohde, Targets for Stabilization of Atmospheric $\mathrm{CO}_{2}$, Science 276 (1997) (5320), pp. 1818-1819. Full Text via CrossRef | View Record in Scopus | Cited By in Scopus

Den Elzen, 1999 Den Elzen, M., et al., 1999. The Brazilian Proposal and other options for International Burden Sharing: an evaluation of methodological and policy aspects using the FAIR model, Technical Report 728001011, RIVM, Bilthoven, The Netherlands.

DOE, 1998 DOE, 1998. Renewable Energy Technology Characterizations, US Department of Energy, Washington, DC, USA.

EIA, 2002 EIA, 2002. International Energy Outlook, Technical Report. DOE/EIA-0484 (2002), DOE (US Department of Energy), Washington, DC, USA.

Grübler and Nakicenovic, 1994 A. Grübler and N. Nakicenovic, International Burden Sharing in Greenhouse Gas Reductions, International Institute for Applied Systems Analysis (IIASA), Laxenburg, Austria (1994).

Höhne and Harnisch, 2002 Höhne, N., Harnisch, J., 2002. Evaluating indicators for the relative responsibility for climate change-alternatives to the Brazilian proposal and global warming potentials. Presented at: Third International Symposium on Non- $\mathrm{CO}_{2}$ Greenhouse Gases (NCGG-3) Maastricht, Netherlands, 21-23 January 2002.

Houghton and Hackler, 2001 Houghton, R., Hackler, J., 2001. Carbon flux to the Atmosphere from Land-Use Changes: 1850 to 1990, ORNL/CDIAC-131, NDP-050/R1. Carbon Dioxide Information Analysis Center (CDIAC), Oak Ridge National Laboratory, US Department of Energy, Oak Ridge, Tenn. USA.

IEA, 2000 IEA, 2000. Experience Curves for Energy Technology Policy, OECD/IEA, Paris.

IPCC, 1996 IPCC, 1996. Revised 1996 Guidelines for National Greenhouse Gas Inventories. In: Houghton, J., et al. (Eds.), vol. 3 Reference Manual IPCC/OECD/IEA: UK Meteorological Office, Bracknell, UK.

IPCC, 1999 IPCC, 1999. IPCC Special Report on Emission Scenarios (SRES). In: Nakicenovic, N., et al. (Eds.), IPCC/UNEP/WMO, Cambridge University Press, Cambridge, UK.

IPCC, 2001a IPCC, 2001a. Climate Change 2001: The Scientific Basis. In: Houghton, J., et al. (Eds.) Contribution of Working Group I to the Third Assessment Report of the IPCC, Cambridge University Press, Cambridge, UK.

IPCC, 2001b IPCC, 2001b. Climate Change 2001: Mitigation.In: Metz, B., et al. (Eds.), Contribution of Working Group III to the Third Assessment Report of the IPCC, Cambridge University Press, Cambridge, UK. 
Manne and Barreto, 2002 Manne, A.S., Barreto, L., 2002. Learn-by-Doing and Carbon Dioxide Abatement, http://www.stanford.edu/group/MERGE/lbd.pdf, visited 14 June 2002.

Marland et al., 2003 Marland, G., Boden, T.A., Andres, R.J., 2003. Global, Regional, and National Fossil Fuel $\mathrm{CO}_{2}$ Emissions. In Trends: A Compendium of Data on Global Change. Carbon Dioxide Information Analysis Center, Oak Ridge National Laboratory, U.S. Department of Energy, Oak Ridge, Tenn., U.S.A. http://cdiac.ornl.gov/trends/emis/meth_reg.htm, visited last 28 April 2005.

Netherlands Ministry of Economic Affairs, 1997 Netherlands Ministry of Economic Affairs, 1997. Renewable Energy-Advancing Power, March 1997.

Persson et al., 2005 Persson, T.A., Azar, C., Lindgren, K., 2005. 'Allocation of $\mathrm{CO}_{2}$ emission permits - Economic incentives for emission reductions in developing countries.' Energy policy to appear.

Sathaye and Wagner, 2003 Sathaye J., Wagner, F., 2003. Least cost burden sharing scenarios from the COBRA energy model. LBNL Report. http://ies.lbl.gov/iespubs/iesgpubs.html.

Siegenthaler and Joos, 1992 U. Siegenthaler and F. Joos, Use of a simple model for oceanic tracer distributions and the global carbon cycle, Tellus B 44 (1992), pp. 186-207. View Record $\underline{\text { in Scopus }}$ | Cited By in Scopus

Tol, 2000 R.S.J. Tol, Modelling the costs of emission reduction: different approaches, PacificAsian Journal of Energy and Environment 10 (2000) (1), pp. 1-7. View Record in Scopus | Cited By in Scopus

UNDP, 2000 UNDP, 2000. World Energy Assessment: Energy and the challenge of sustainability. In: J. Goldemberg (Ed.), UNDP/UNDESA/WEC, New York, USA.

UNFCCC, 1992 UNFCCC, 1992. United Nations Framework Convention on Climate Change http://unfccc.int/resource/docs/convkp/conveng.pdf, visited on 5 February 2003.

UNFCCC, 2002 UNFCCC, 2002. Document FCCC/SBSTA/2002/INF.14.

Van Aardanne et al., 2001 J. Van Aardanne et al., A 1×1 resolution dataset of historical anthropogenic trace gas emissions for the period 1890-1990, Global Biogeochemical Cycles 15 (2001) (4), pp. 909-928.

Van Vuuren et al., 2003 Van Vuuren, D.P., den Elzen, M.G.J., Berk, M.M., Lucas, P., Eickhout, B., Eerens, H., Oostenrijk, R., 2003. Regional costs and benefits of alternative post-Kyoto climate regimes, RIVM Report 728001025/2003, Bilthoven, Netherlands. 


\section{Appendix A. Summary of COBRA-model assumptions and constraints}

In this appendix we briefly state the general assumptions entering COBRA-Energy, more details can be found in Sathaye and Wagener (2003).

General assumptions: Our foremost assumption is that the system we are studying can indeed be represented in a linear model. This requires that we absorb all the non-linearities in larger models into linear parameters determined through external mechanisms. ${ }^{10}$ For example, the regional future energy demand is an external parameter taken from the SRES, and the cost function is linear in the fuel use and is a sum over all years 2000-2100. We thus assume complete knowledge of future parameters such as the cost structure and technological developments, for example, improvements on electricity conversion efficiencies, and optimize the overall (discounted) costs, but not the regional costs or the costs at a particular point in time. The carbon emission and concentration part of the model uses the standard linear approximation of the Bern CC model (Siegenthaler and Joos, 1992).

Furthermore, in the modelling of future emission scenarios we focus entirely on emissions from fossil fuel consumption, that is, we assume that emissions from LU/LUCF follow the path outlined in the AIM A1B scenario and form the background emissions (these are important in the calculation of future $\mathrm{CO}_{2}$ concentrations in the atmosphere). As a consequence, reduction targets calculated in the burden-sharing regime can in this version of the model only be achieved by reducing emissions from fossil fuel consumption. Moreover, in order to keep the model fairly concise we deliberately do not take into account the possibility of large scale sequestering. Moreover, greenhouse gases other than $\mathrm{CO}_{2}$ are not considered in our analysis. Estimates of historic $\mathrm{CO}_{2}$ emissions were published by a number of research groups in recent years, e.g., CDIAC (Marland et al., 2003; Houghton and Hackler, 2001), EDGAR-HYDE (Van Aardanne et al., 2001) and IIASA (Grübler and Nakicenovic, 1994). ${ }^{11}$ In COBRA-Energy we use CDIAC data for the period 1900-1995 and interpolate for the years 1995-2000. As one goes back in time estimates of anthropogenic GHG emissions become more uncertain, both for land-use related emissions and emissions from fossil fuel burning. However, the contribution of early emissions to cumulative emissions becomes less important as past activity levels were comparatively low.

Past and future carbon emissions from fossil fuel burning can be estimated from data on fuel consumption and fuel specific carbon content data for coal, oil and natural gas. In our benchmark scenario we use the fuel consumption projection in the AIM A1B scenario for the period 20002100 , assuming that the apparent primary consumption can be used in this context. The fuel specific carbon content varies mildly across producing regions, but due to fuel trade between regions it is difficult to track down specific carbon contents for individual consuming regions. For simplicity we therefore use IPCC default values for coal, oil and natural gas, respectively (IPCC, 1996, p.1.13), ${ }^{12}$ all other fuels are assumed to be strictly carbon neutral. Moreover, the AIM A1B reference scenario provides $\mathrm{CO}_{2}$ emission data from land use, which we use for all three scenarios in order to account for all anthropogenic emissions. The regional energy demand is not calculated dynamically by our model but rather taken from the AIM A1B scenario for the period 2000-2100 as exogenous parameters, beyond 2100 the trend in demand growth is extrapolated. In COBRA-Energy we require that the demand both in the electricity sector and the non-electric sector be met until 2180. Obviously, other SRES scenarios provide different sets of 
demand data, and we also note that recent mid-term projections see developments that are different from AIM A1B data. $\underline{13}$

Resource constraints: Global energy resources for the 21st century are ample, but they are not evenly distributed geographically, not always easily accessible and often little developed. As unconventional sources for fossil fuels come into view and as future economic potentials may approach today's technical potentials, it seems reasonable to impose constraints only on the global supply of biomass, wind power and hydroelectricity, while the supply from the other fuels and technologies listed in Table 1 is essentially unlimited during the 21st century (see, e.g., UNDP, 2000). Unlike fossil fuels, wind and sun are intermittent energy sources. This has implications on their place in a region's fuel mix. IEA (2000) estimates that 10-20 percent of a region's electricity generation capacity could be made of wind turbines without adverse economic or operational effects. Beyond that advanced storage, backup and load management systems are needed. For COBRA-Energy we assume that such systems would be available by 2050 so that the full technical potential would be available and, for simplicity, at constant additional cost. $\underline{14}$

Other economic beyond resource availability and cost structure of the various fuel options are implemented in COBRA-Energy as constraints on the rate of change in consumption patterns:

- First, it is observed that technologies penetrate the markets gradually. Capacity, infrastructure and consumer acceptance can only be built up gradually. In COBRA-Energy this type of constraint is implemented by imposing fuel-specific upper bounds on the growth in fuel use. In the baseline scenario these maximum growth rates correspond to a corridor around the more aggregated regional fuel use data in the SRES reference scenario. For the least cost and burden sharing scenarios we then relax these bounds in order to accommodate the required, more rapid transition to less carbon-intensive fuels.

- Second, the dynamics of fuel mix changes is approximated by requiring also that the fuel use from one period to the next cannot decrease by more than a certain percentage: this restricts the retirement age and reflects the longevity of investments in the energy sector without modelling the life cycle of individual plants explicitly. As a default value we use a maximum decrease of 30 percent over 10 years for each of the fuel types, which corresponds to a lifetime of approximately 28 years in an exponential decay. ${ }^{15}$

Energy costs in COBRA-Energy are determined exogenously from four sets of parameters: (1) the initial cost of the year 2000, (2) parameters that drive fuel prices, (3) technology-specific learning parameters, and finally (4) conversion efficiency improvements, which influence the cost for electricity generation as well. For direct fuel uses we assume that energy costs are entirely driven by fuel costs, $\frac{16}{}$ while in the electricity sector we also take capital, operation and maintenance costs into account. Estimates of the parameters were taken from standard references, such as UNDP (2000), EIA (2002), and DOE (1998). Rather than modelling the learning-by-doing dynamically we have fine-tuned exogenously our cost changes to make them consistent with the learning rates from Manne and Barreto (2002) and IEA (2000). A detailed description of all parameter values entering COBRA-Energy, including efficiency projections, can be found in Sathaye and Wagner (2003). Energy cost parameters used for the year 2000 are 
summarized in Table 2, and Fig. 17 which shows the assumed development of electricity production costs in the OECD90 region for the various fuel types available in the model. Let us emphasize again that this is a static description of the energy cost development, though with strong input for the appropriate parameters from the dynamic approaches. COBRA-Energy was first conceived as an Excel application but has since grown into a GAMS version.

Table 2. Estimated energy costs for electricity generation and direct fuel use (e.g for transport, industry, residential, etc.) in the year 2000

\begin{tabular}{|c|c|c|c|c|c|c|c|c|}
\hline & \multicolumn{2}{|l|}{ OECD90 } & \multicolumn{2}{|l|}{ REF } & \multicolumn{2}{|l|}{ ASIA } & \multicolumn{2}{|l|}{ ALM } \\
\hline & $\begin{array}{l}\text { Elec. } \\
\text { (US } / \text { /kWh) }\end{array}$ & $\begin{array}{l}\text { Direct } \\
\text { (US\$/GJ) }\end{array}$ & $\begin{array}{l}\text { Elec. } \\
\text { (US } \$ / k W h)\end{array}$ & $\begin{array}{l}\text { Direct } \\
\text { (US\$/GJ) }\end{array}$ & $\begin{array}{l}\text { Elec. } \\
\text { (US } / \text { /kWh) }\end{array}$ & $\begin{array}{l}\text { Direct } \\
\text { (US\$/GJ) }\end{array}$ & $\begin{array}{l}\text { Elec. } \\
\text { (US } \$ / k W h)\end{array}$ & $\begin{array}{l}\text { Direct } \\
\text { (US\$/GJ) }\end{array}$ \\
\hline Coal & 2.7 & 1 & 2.7 & 1 & 2.2 & 0.5 & 2.7 & 1 \\
\hline Oil & 5.6 & 4 & 5.6 & 4 & 5.6 & 4 & 5.6 & 4 \\
\hline Gasoline & - & 4 & - & 4 & - & 4 & - & 4 \\
\hline Diesel & - & 4 & - & 4 & - & 4 & - & 4 \\
\hline Nat. Gas & 4.4 & 3 & 4.4 & 3 & 4.4 & 3 & 4.4 & 3 \\
\hline Nuclear & 4 & - & 4 & - & 4 & - & 4 & - \\
\hline Hydroelectric. & 5 & - & 5 & - & 5 & - & 5 & - \\
\hline Biomass & 6.4 & 2 & 6.4 & 2 & 6.4 & 2 & 6.4 & 2 \\
\hline Wind & 7 & - & 7 & - & 7 & - & 7 & - \\
\hline $\begin{array}{l}\text { Solar (incl. } \\
\text { Geoth.) }\end{array}$ & 12 & - & 12 & - & 12 & - & 12 & - \\
\hline
\end{tabular}

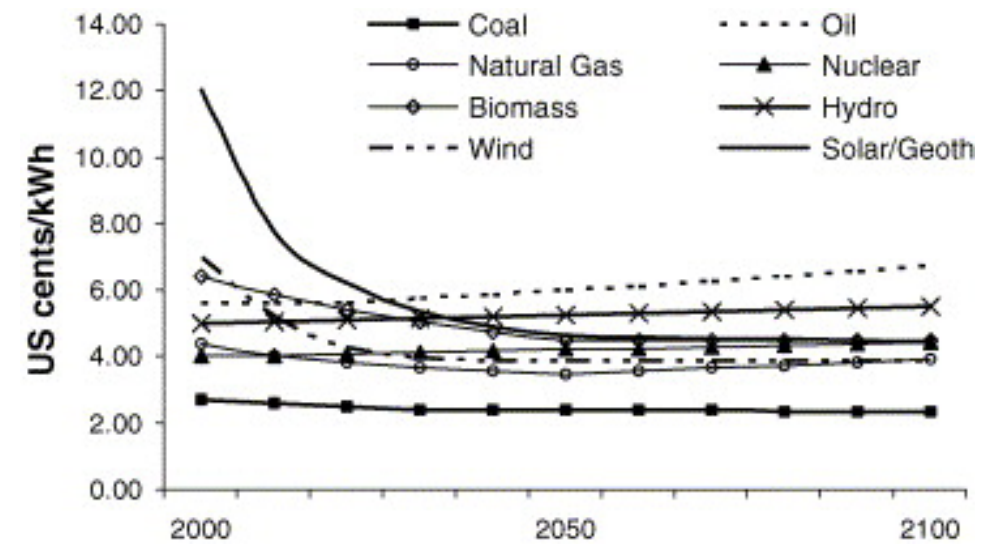

Fig. 17. Example of projected cost for electricity production in OECD90, 2000-2100 $\frac{17}{\text {. }}$ 


\section{Notes:}

${ }^{1}$ While pre-industrial concentration levels of $\mathrm{CO}_{2}$ in the atmosphere were about 280 ppmv (parts per million in volume), current levels are around $370 \mathrm{ppmv}$, and are increasing faster than in previous decades.

${ }^{2}$ In this paper we use the more concise term 'burden sharing' in place of 'differentiation of future commitments'.

${ }^{3}$ For alternative approaches to regional permit allocation, such as Multi-Stage and Per Capita Convergence, see Van Vuuren et al. (2003).

${ }^{4}$ For the exact definition of the IPCC SRES regions, see IPCC (1999), Appendix III.

${ }^{5}$ Furthermore, we include projections for R\&D of technologies that reduce energy demand (such as improvement of end-use efficiencies) only implicitly, i.e. insofar as they are already been taken into account in the demand projection of the benchmark SRES A1B scenario.

${ }^{6}$ In fact, one could go even further and estimate the share of a country's contribution to a temperature increase or the sea level rise, either based on today's measurements or on estimated impacts in the future: there is thus, a whole variety of measures of 'responsibility to reduce', which can be classified as forward-looking, backward-looking, backward-discounting, etc. (see Höhne and Harnisch, 2002). We have chosen a simple measure that is backward looking and can be applied to individual gases, such as $\mathrm{CO}_{2}$ separately. See also UNFCCC (2002).

${ }^{7}$ For simplicity, in this paper "Annex I" and "non-Annex I" are synonyms for OECD90+REF and ASIA+ALM, respectively.

${ }^{8}$ The same is then qualitatively and obviously true for the cumulative emissions.

${ }^{9}$ Two points need to be made here. First, it needs to be emphasized that this is simply an issue of rendering the assumptions about the economic development and emissions consistent with the burden sharing prescription. However, it is true that it could be perceived as a loophole of the burden sharing, but one should carefully distinguish the allocation of permits from the amount of reductions that can be or are actually achieved. Second, the sensitivity of this effect is moderately high due to feedback mechanisms. The additional burden for the other regions may turn out to be unbearable, so that the burden sharing prescription may become infeasible.

${ }^{10}$ Others have taken the same approach before us, for a recent example, see e.g., Persson et al. (2005). See also Tol (2000) and Section 8.1 in IPCC (2001b) for a brief review of various kinds of economic modelling approaches.

11 These data sets cover periods as far back as 1750 . For a comparison of the data sets see Section 2 of Den Elzen et al. (1999). Here we only take into account $\mathrm{CO}_{2}$ emissions after 1900.

$\underline{12}$ We note that with these values for the fuel specific carbon content, the corresponding emission factors and the activity data for the year 2000 of the AIM A1B scenario we obtain slightly higher $\mathrm{CO}_{2}$ emission values than the ones given in the SRES. This may be due to the fact that we do not take into account regional differences in carbon content for the various fuels. Moreover we have an aggregated fuel structure and in this context do not distinguish primary from secondary fuels. Finally, neither bunker fuels nor process emissions are treated in our model.

$\underline{13}$ The reference scenario of EIA (2002) sees a total primary demand in 2020 that is approximately 10 percent lower than AIM A1B projections, mainly due to a lower demand in developing countries. Projections on growth rates of individual fuels were taken from EIA and adjusted for AIM A1B. 
$\underline{14}$ The Netherlands Ministry of Economic Affairs (1997) estimates that back-up costs for intermittent sources could amount to $2-3$ cents/kWh.

15 There are examples in which the real mid- to long-term behavior is noticeably different; for instance, Germany's intention to fix the (average) retirement age of its nuclear power plants at 34 years is poorly approximated by an exponential decay. However, on a larger regional scale and across sectors the exponential decay is a good approximation.

$\underline{16}$ That is, for lack of data at such an aggregate level costs for infrastructure are all absorbed into fuel costs.

$\underline{17}$ For the other regions, as well as for direct energy uses, analogous input data were derived. 